Thorax (1976), 31, 137.

\title{
Inhibition of exercise-induced asthma by different pharmacological pathways
}

\author{
S I M O N O D F R Y a nd P E T E R K Ö N I G \\ Department of Paediatrics and Neonatal Medicine, Hammersmith Hospital, London
}

\begin{abstract}
Godfrey, S. and König, P. (1976). Thorax, 31, 137-143. Inhibition of exercise-induced asthma by different pharmacological pathways. Exercise-induced asthma (EIA) was provoked by standardized treadmill running for 6 minutes in 15 asthmatic children. The tests were carried out after the administration of a placebo, salbutamol, sodium cromoglycate, choline theophyllinate, and atropine methonitrate aerosol in randomized fashion on different days. The mean post-exercise percent fall in peak expiratory flow rate was $45 \cdot 2,4 \cdot 1,19 \cdot 6,18 \cdot 3$, and $24 \cdot 9$ respectively. The proportion of children having significant amelioration of their EIA compared with those taking the placebo was $100 \%$ for salbutamol, $80 \%$ for cromoglycate and theophyllinate, and $60 \%$ for atropine. Salbutamol, choline theophyllinate, and atropine were bronchodilators at rest whereas cromoglycate was not, and the ability to suppress EIA was unrelated to bronchodilator effect. Even after bronchodilatation at rest, further bronchodilatation occurred during the exercise period.
\end{abstract}

Exercise of appropriate type and severity provokes a controlled, brief but severe attack of airways obstruction in the asthmatic patient. The maximal response is obtained after some 6 to 8 minutes of running at approximately two-thirds of the aerobic working capacity (Godfrey, Silverman, and Anderson, 1973). Many drugs used to treat asthma have been shown to inhibit exercise-induced asthma (EIA) in various studies or groups of subjects. Thus significant inhibition has been obtained with sympathomimetics, theophylline derivatives, and sodium cromoglycate (Jones, Wharton, and Buston, 1963; McNeill et al., 1966; Davies, 1968; Silverman and Andrea, 1972). On the other hand, no inhibition has been found with antihistamines (Jones et al., 1963) or with steroids in most subjects (König, Jaffe, and Godfrey, 1974). The position of atropine is disputed, some studies in individual patients showing inhibition (Crompton, 1968) but most showing inhibition in only a small proportion of subjects (Jones et al., 1963; Sly et al., 1967; Silverman, 1973). In view of the recent evidence of the role of the vagus in canine and human allergeninduced asthma (Gold, Kessler, and $\mathrm{Yu}, 1972$; $\mathrm{Yu}$, Galant, and Gold, 1972) and the similarity between exercise and antigen-induced asthma as far as the response to sodium cromoglycate or steroids is concerned (König et al., 1974), these results with atropine are perhaps surprising.

Most previous studies of drugs in EIA have not compared different agents in the same subjects, and the type or form of exercise has varied from study to study. Since this can have such a serious effect on the EIA (Godfrey et al., 1973) and because some of these drugs cause bronchodilatation at rest, we decided to carry out a comparative study in a single group of asthmatic children using a standardized treadmill exercise test.

\section{SUBJECTS AND METHODS}

Studies were carried out on a group of 15 asthmatic children aged 5 to 14 (mean 8.7) years during the course of their routine investigation for which we normally employ exercise tests. Because of the large variability of the response over periods longer than one week (Silverman and Anderson, 1972), the studies were carried out in two separate one-week periods. In the first period, all $\mathbf{1 5}$ children were tested with a placebo, salbutamol, choline theophyllinate, and sodium cromoglycate in random order with only one active drug used on any one day. In the second period, seven of the children were retested with placebo and then with atropine on the same day but with a 2-hour gap between tests. We have previously shown that this gap is sufficient to allow a full response in the second test (Godfrey et al., 1973).

All drugs were given in normal therapeutic doses, and these together with the routes of administration of the drugs are shown in Table I. Salbutamol was given from a pressurized aerosol in all but two 
T A B L E I

ROUTE OF ADMINISTRATION AND DOSE OF DRUG

\begin{tabular}{|c|c|c|}
\hline Drug & Route and Dose & No. Tested \\
\hline Placebo & $\begin{array}{l}\text { Inhaled lactose powder } \\
\text { Inhaled aerosol propellent } \\
\text { Oral lactose tablet } \\
\text { Pressurized aerosol, } 200 \mu \mathrm{g} \\
\text { Oral tablet, 3-4 mg }\end{array}$ & $\begin{array}{r}13 \\
1 \\
1 \\
13 \\
2\end{array}$ \\
\hline $\begin{array}{l}\text { Choline } \\
\text { theophyllinate } \\
\text { Sodium } \\
\text { cromoglycate } \\
\text { Atropine }\end{array}$ & $\begin{array}{l}\text { Oral tablet, } 100-200 \mathrm{mg} \\
\text { Inhaled powder, } 20 \mathrm{mg} \\
\text { Wet aerosol and face-mask, } \\
0.2 \% \text { solution, flow rate } \\
91 / \mathrm{min} \text { for } 3 \text { min }\end{array}$ & $\begin{array}{r}15 \\
15 \\
7\end{array}$ \\
\hline
\end{tabular}

patients to whom it was given by mouth. Choline theophyllinate was given by mouth and sodium cromoglycate by the standard spinhaler device. Atropine was given by nebulization of a $0.2 \%$ solution of atropine methonitrate using a Wright's nebulizer for 3 minutes at a flow rate of $91 / \mathrm{min}$ (modified from Altounyan (1964)). Placebos were given by mouth, resembling salbutamol tablets in one child, by inhaled aerosol propellant in one child, by spinhaler as used for cromoglycate in 13 children, and again by nebulization of saline to simulate atropine in the seven children studied in the second period. Oral drugs were given 2 hours before exercise, and inhaled drugs 5 to 10 minutes before exercise. No other medications were taken for 12 hours before the tests. The studies were carried out in a single-blind fashion by a technician who did not know what result to expect and were analysed by the investigators after completion of the whole series of tests.

The exercise test was carried out on a motor-driven treadmill, as described by Connolly and Godfrey (1970). The child ran continuously for 6 minutes up a gradient of $10 \%$ at a speed of approximately $5 \mathrm{kph}$ $(3 \mathrm{mph})$ so as to produce a heart-rate of 170 to 180 beats per minute. The same settings were used for each test in any one child. Peak expiratory flow rate (PEFR) was measured before, every 2 minutes during, and at intervals up to 20 minutes after exercise using a Wright peak flow meter and taking the best of three attempts each time. Normal values were taken from the data of Godfrey, Kamburoff, and Nairn (1970). Results of exercise tests were expressed in terms of the following indices based on the PEFR measured immediately before exercise but after giving the drug or placebo.

$$
\% \text { Rise }=\frac{\begin{array}{c}
\text { Highest PEFR during } \\
\text { exercise }
\end{array}-\begin{array}{c}
\text { Resting } \\
\text { PEFR }
\end{array}}{\text { Resting PEFR }} \times 100
$$

$$
\% \text { Fall }=\frac{\begin{array}{l}
\text { Resting }- \text { Lowest PEFR after } \\
\text { PEFR }
\end{array}}{\text { Resting PEFR }}-\times 100
$$

In addition, these indices were also expressed on a relative scale by converting the PEFR values to the percent of expected before calculating the results (see below).

A preliminary analysis showed no difference in response between inhaled or oral salbutamol, and the data have therefore been treated together. Likewise there was no difference in response to the three forms of placebo, and so the results of the initial set of 15 placebo studies have been used for comparison. A drug result was considered to be significant if the $\%$ 윽 fall differed by more than $25 \%$ from the placebo result because we found this to be the coefficient of $\vec{D}$ variation of the difference of two placebo tests carried out on one day in a group of 80 asthmatic children:

$$
\text { Coefficient of variation }=\frac{\begin{array}{c}
\text { SD difference } \\
\text { between } 2 \text { tests }
\end{array}}{\sqrt{ } 2 \times \text { mean }} \times 100
$$

Silverman and Anderson (1972), using a different $\overrightarrow{\bar{O}}$ method of calculation based on multiple testing, $\exists$ found a coefficient of variation of $22 \%$ for repeated testing within a one-week period.

For comparison between studies, a paired $t$ test was used, and differences were considered significant if $P \leqslant 0.05$.

\section{RESULTS}

The individual results of the tests are given in Table II. The values for the resting PEFR before the drugs were given were very similar for all tests, the means lying between 69 and $77 \%$ of expected without any significant differences. After the administration of salbutamol, choline theophyllinate, and atropine, of there was a significant bronchodilatation with mean $N$ rises in PEFR of $18 \%, 14 \%$, and $18 \%$ respectively. N In contrast, there were insignificant rises after placebo $\sigma$ and sodium cromoglycate of $5 \%$ and $2 \%$ respectively. These effects on resting PEFR are shown in Figure 1.

The mean results of the exercise tests are shown in Figure 2. There was a significant degree of bronchodilatation during exercise in all tests, which was greatest for the cromoglycate study, but differences $\stackrel{\mathbb{D}}{\circ}$ were not significant. After exercise with placebo there $\frac{\sim}{\mathbb{Q}}$ was a severe degree of bronchoconstriction which was $\varrho$ significantly less in the tests following all of the active drugs. The $\%$ fall in PEFR after the salbutamol 8 


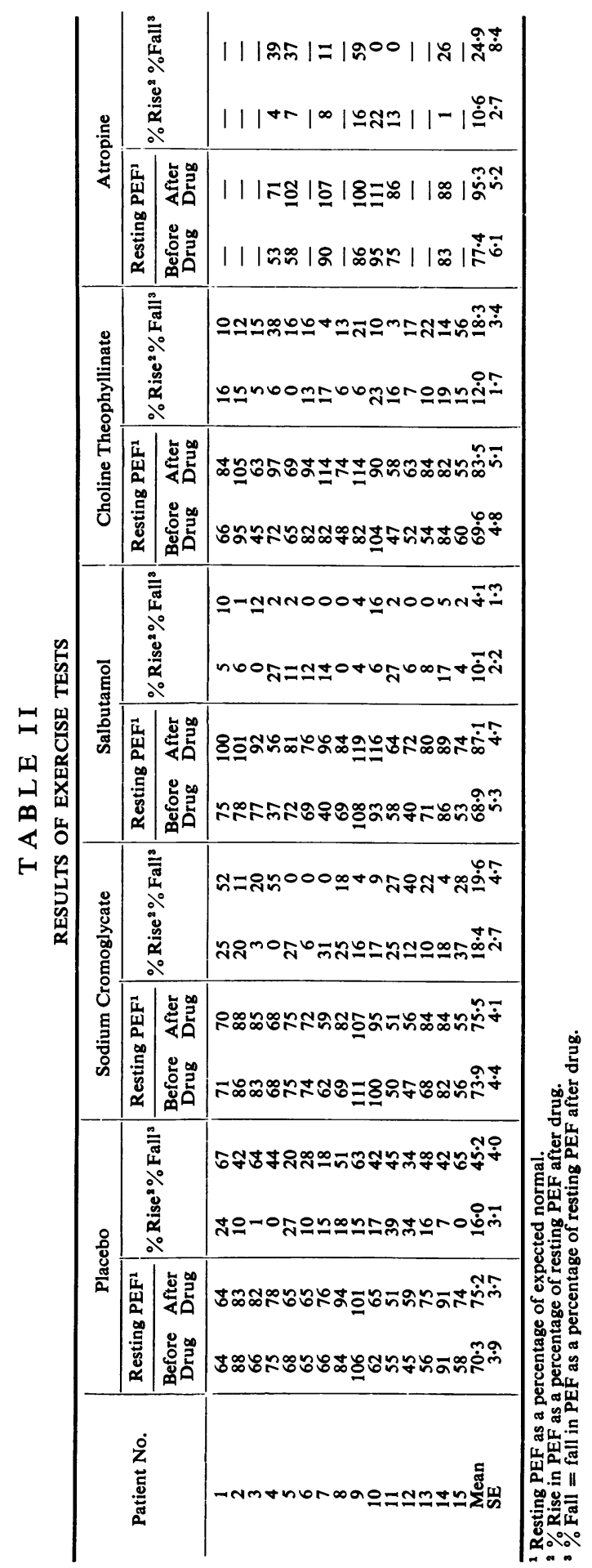




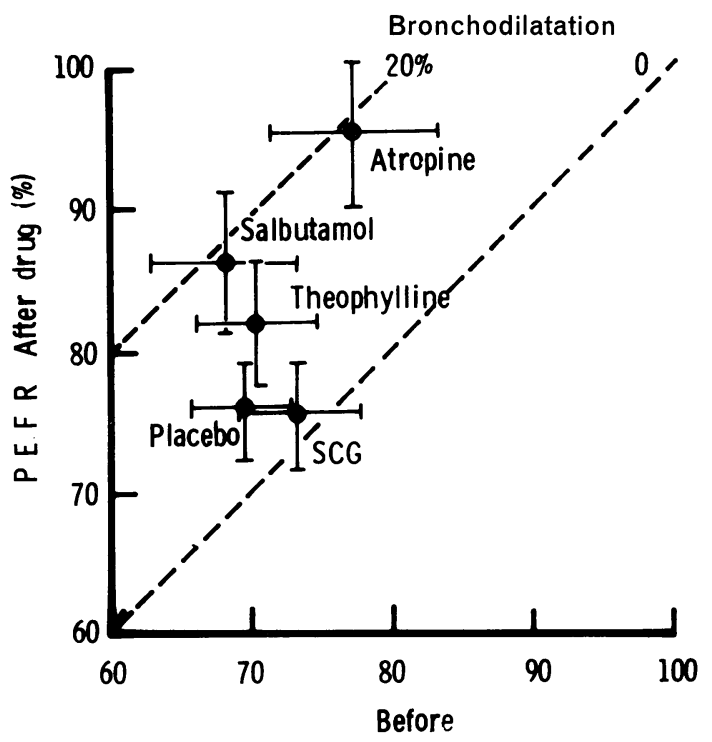

FIG. 1. Peak expiratory flow rate (PEFR) before inhaling the drugs is plotted against PEFR after inhaling the drugs, all measurements being made at rest before the start of the exercise test. The points indicate the mean value for the group of subjects and the bars indicate $\pm 1 S E M$. SCG = sodium cromoglycate.

Salbutamol

SCG

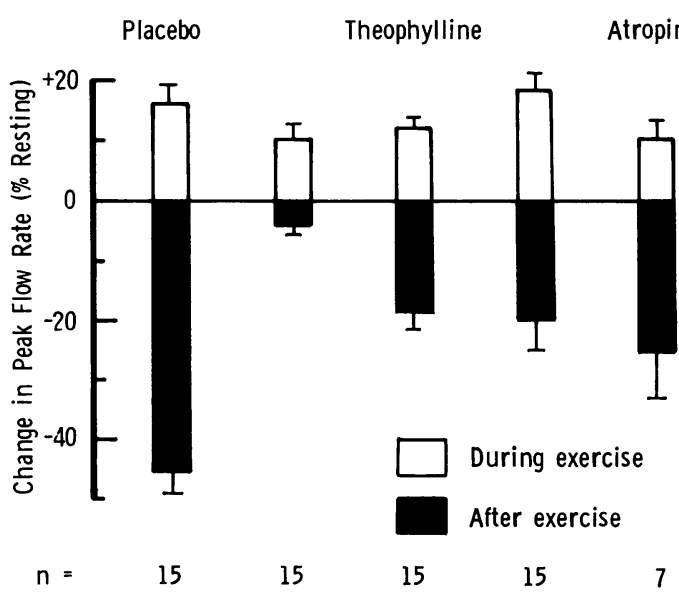

FIG. 2. Bronchodilatation during exercise and bronchoconstriction after exercise expressed as $\%$ change from the resting value immediately before exercise but after receiving the drugs indicated. The bars show \pm 1 SEM. exercise test was significantly less than that with the other three active drugs, which did not differ from each other. The blocking effect was calculated as follows:

$$
\text { Block } \%=\frac{\begin{array}{c}
\% \text { Fall on } \\
\text { placebo }
\end{array}-\begin{array}{c}
\% \text { Fall on } \\
\text { drug }
\end{array}}{\% \text { Fall on placebo }} \times 100
$$

Using this index, the mean block was $92 \%$ for salbutamol, $58 \%$ for choline theophyllinate, $60 \%$ for sodium cromoglycate, and $45 \%$ for atropine. Again, salbutamol was significantly more effective than the other drugs, which did not differ from each other.

Because of the initial bronchodilatation with some drugs, the results have also been expressed on a scale of PEFR as \% expected, as shown in Figure 3. The bronchodilatation due to the drug is indicated by the arrow which shows the rise in PEFR at rest after the drug has been given. The bars then show the subsequent bronchodilatation during exercise and bronchoconstriction after stopping. When analysed in this way, the conclusions are just the same as those above, the post-exercise fall in PEFR being $35 \%$ for placebo, $4 \%$ for salbutamol, $14 \%$ for choline theophyllinate, $14 \%$ for sodium cromoglycate, and $23 \%$ for atropine. This format shows the impressive bronchodilatation seen during exercise, particularly in the atropine tests when the mean level rose to $106 \%$ of expected normal.

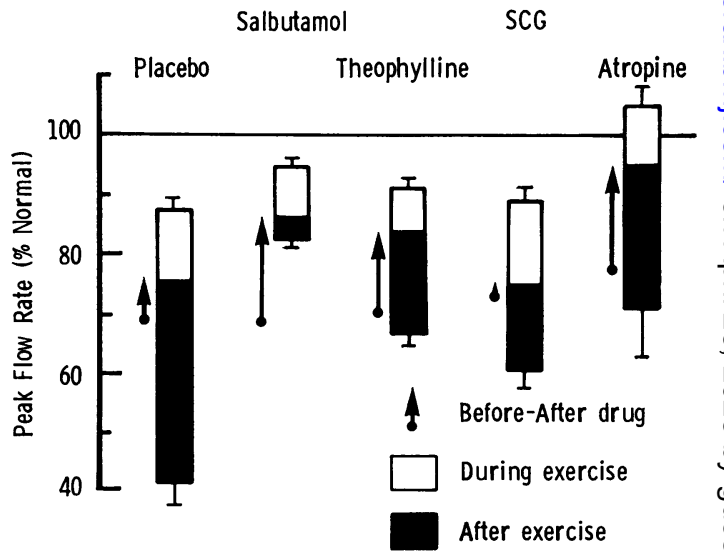

FIG. 3. Same data as in Fig. 2 but expressed on a scale showing the peak flow rate as $a \%$ of the expected value. The arrows indicate the change occurring at rest before exercise as a result of giving the drugs indicated. The subsequent bronchodilatation during exercise and bronchoconstriction after exercise are shown relative to the peak flow rate after the drug. 
T A B L E I I I

INDIVIDUAL SIGNIFICANCE OF RESPONSES

\begin{tabular}{|c|c|c|c|c|}
\hline Subject & $\begin{array}{l}\text { Sodium } \\
\text { Cromo- } \\
\text { glycate }\end{array}$ & Salbutamol & $\begin{array}{l}\text { Choline } \\
\text { Theophyl- } \\
\text { linate }\end{array}$ & Atropine \\
\hline $\begin{array}{r}1 \\
2 \\
3 \\
4 \\
5 \\
6 \\
7 \\
8 \\
9 \\
10 \\
11 \\
12 \\
13 \\
14 \\
15\end{array}$ & $\begin{array}{l}0 \\
++ \\
++ \\
0 \\
++ \\
++ \\
++ \\
++ \\
++ \\
++ \\
+ \\
0 \\
++ \\
++ \\
++\end{array}$ & $\begin{array}{l}++ \\
++ \\
++ \\
++ \\
++ \\
++ \\
++ \\
++ \\
++ \\
++ \\
++ \\
++ \\
++ \\
++ \\
++\end{array}$ & $\begin{array}{l}++ \\
++ \\
++ \\
0 \\
0 \\
+ \\
++ \\
++ \\
++ \\
++ \\
++ \\
++ \\
++ \\
++ \\
++\end{array}$ & $\begin{array}{l}+ \\
\mathbf{0} \\
++ \\
0 \\
++ \\
++ \\
0\end{array}$ \\
\hline
\end{tabular}

The degree of protection from EIA has also been assessed for each individual patient (Table III). The block was considered as insignificant ( 0 ) if it was less than $25 \%$ (the coefficient of variation - see methods), as moderate $(+)$ if it was between 25 and $50 \%$, and good $(++)$ if it was more than $50 \%$. It was found that with salbutamol the block was good in all children, and with choline theophyllinate it was good in 10 children, moderate in two children, and insignificant in the other three; with sodium cromoglycate it was good in 11, moderate in one, and insignificant in the other three. As far as atropine was concerned, only four of the seven children had significant blocks, which were good in three and moderate in the other one. Thus, although the mean protection by atropine was significant ( $\%$ fall less than in placebo test) this was really due to the good effect in only four of seven $(60 \%)$ of the children.

There was no significant correlation between the degree of bronchodilatation produced at rest and the magnitude of the block of EIA by any of the drugs.

\section{DISCUSSION}

This study has shown that EIA may be largely prevented by premedication with drugs which act through different pathways, but also that the response to some drugs varies between subjects. We have confirmed the efficacy of a sympathomimetic agent (salbutamol) in preventing EIA and the relatively good effects of a phosphodiesterase inhibitor (choline theophyllinate) and sodium cromoglycate as reported by others (Jones et al., 1963; McNeill et al., 1966; Davies, 1968; Eggleston et al., 1972; Silverman and Andrea, 1972). We gave these drugs in the normal therapeutic doses, and on this basis it appears that salbutamol was most effective and theophylline and sodium cromoglycate about the same as each other.

On a superficial level it also appears that atropine blocks EIA since the mean percent fall in PEFR was less after the drug run than after the placebo run. However, when the individual studies are analysed, it can be seen that only four of the seven children had significant protection (Table III), and in the remaining three children the difference between tests was no greater than between two placebo tests.

This emphasizes the extreme caution needed when studying drug effects on EIA and shows the importance of considering the inherent variability of a test. Moreover, since placebos themselves have been shown to reduce EIA significantly in up to $40 \%$ of children (Godfrey and Silverman, 1973), it is essential to compare the drug test with a placebo test and not merely with a different drug test as both drugs might be acting merely through a placebo effect. Because of these factors it is essential that the form of exercise test should produce a large response and a clear-cut effect, and that it shouuld be as reproducible as possible. We have previously pointed out that this is best achieved by standardized running in the manner described, while other types of exercise, such as walking or cycling, and other patterns of exercise, such as progressively increasing or prolonged work, are much less reliable (Anderson, Connolly, and Godfrey, 1971; Silverman and Anderson, 1972; Godfrey et al., 1973). Failure to allow for these factors probably accounts for some of the confusion over the effects of drugs on EIA. Thus Poppius and Salorinne (1973) failed to demonstrate inhibition of EIA by salbutamol but gave no control or placebo data and used progressive ergometer exercise. Their findings are totally at variance with the results of the present study and with almost every other published study on the effect of sympathomimetics.

We have shown that the inhibition of EIA is unrelated to bronchodilator activity at rest so that sodium cromoglycate had no resting effect on PEFR while the other drugs caused significant bronchodilatation and yet sodium cromoglycate was as effective on EIA as theophylline. Equally when considering the bronchodilators, there was no correlation between this effect and their power to block EIA. If a drug possesses bronchodilator activity, it is impossible to define its site of action in EIA, but sodium cromoglycate must clearly act in a different way from the other drugs and is effective only in preventing induced asthma. Much attention has recently been paid to the vagus, and it has been suggested that antigen-induced asthma, histamineinduced asthma, and possibly other types of asthma may have a final common pathway through a vagal reflex (Altounyan, 1964; Booij-Noord et al., 1970; 
Yu et al., 1972). It seems inherently unlikely that this could be true for EIA since our study has shown a significant atropine block in only about $60 \%$ of children, despite using a dose which caused bronchodilatation in every case (doubling the specific airways conductance which we measured plethysmographically) and raising the resting heart-rate by a mean of 12 beats per minute. Our results with inhaled atropine agree with those obtained using intravenous atropine (Jones et al., 1963; McNeill et al., 1966; Silverman, 1973), subcutaneous atropine (Sly et al., 1967), or inhaled anticholinergic drug (Poppius, Salorinne, and Viljanen, 1972). It is possible that the PEFR measurement is not sensitive enough to detect small changes in airways calibre and hence some beneficial effect of atropine may have been missed. However, Benatar and König (1974) have shown excellent agreement between the PEFR indices of EIA and changes in the flow-volume curve, while Fisher et al. (1970) were unable to detect any benefit of atropine on EIA using a whole-body plethysmograph.

Finally, it is worth noting the bronchodilatation which occurs during the course of the exercise period. This was proportionately greater in the placebo and sodium cromoglycate tests (Fig. 2) but the other drugs were bronchodilators and had raised the resting PEFR before exercise to a point where there was less potential for further rise (Fig. 3). On this basis all four drugs and placebo gave a similar rise during exercise of $8 \%$ to $13 \%$. Even so, in the atropine exercise test the PEFR rose above the expected normal value despite the fact that atropine was no better bronchodilator at rest than salbutamol or theophylline. This suggests that vagal tone might still be operating during exercise in the presence of salbutamol, theophylline, or sodium cromoglycate but is inhibited by atropine.

In conclusion we have shown that exercise-induced asthma is normally blocked in all children by salbutamol, in $80 \%$ of children by choline theophyllinate or sodium cromoglycate, but in only some $60 \%$ of children by atropine.

We wish to thank Miss M. McMichen for her excellent technical assistance.

\section{REFERENCES}

Altounyan, R. E. C. (1964). Variation of drug action on airway obstruction in man. Thorax, 19, 406.

Anderson, S. D., Connolly, N. M., and Godfrey, S. (1971). Comparison of bronchoconstriction induced by cycling and running. Thorax, 26, 396.

Benatar, S. R. and König, P. (1974). Maximal expiratory flow and lung volume changes associated with exercise-induced asthma in children and the effect of breathing a low-density gas mixture. Clinical Science and Molecular Medicine, 46, 317.
Booij-Noord, H., Orie, N. G. M., Berg, W. C., and de Vries, K. (1970). Results of provocation of human bronchial airways with allergic and non-allergic stimuli and of drug protection tests. In Bronchitis III, edited by N. G. M. Orie and R. Van der Lende, p. 316. Royal Vangorcum, Assen.

Connolly, N. and Godfrey, S. (1970). Assessment of the child with asthma. Journal of Asthma Research, 8, 31 .

Crompton, G. K. (1968). An unusual example of exerciseinduced asthma. Thorax, 23, 165.

Davies, S. E. (1968). The effect of disodium cromoglycate on exercise-induced asthma. British Medical Journal, 3, 593.

Eggleston, P. A., Bierman, C. W., Pierson, W. E., Stamm, S. J., and Van Arsdel, Jr., P. P. (1972). A double-blind trial of the effect of cromolyn sodium on exerciseinduced bronchospasm. Journal of Allergy and Clinical Immunology, 50, 57.

Fisher, H. K., Holton, P., Buxton, R. St. J., and Nadel, J. A. (1970). Resistance to breathing during exerciseinduced asthma attacks. American Review of Respiratory Disease, 101, 885.

Godfrey, S., Kamburoff, P. L., and Nairn, J. R. (1970). Spirometry, lung volumes and airway resistance in normal children aged 5-18 years. British Journal of Diseases of the Chest, 64, 15.

- and Silverman, M. (1973). Demonstration by placebo response in asthma by means of exercise testing. Journal of Psychosomatic Research, 17, 293.

- - , and Anderson, S. D. (1973). Problems of interpreting exercise-induced asthma. Journal of Allergy and Clinical Immunology, 52, 199.

Gold, W. M., Kessler, G. F., and Yu, D. Y. C. (1972). Role of vagus nerves in experimental asthma in allergic dogs. Journal of Applied Physiology, 33, 719.

Jones, R. S., Wharton, M. J., and Buston, M. H. (1963). The place of physical exercise and bronchodilator drugs in the assessment of the asthmatic child. Archives of Disease in Childhood, 38, 539.

König, P., Jaffe, P., and Godfrey, S. (1974). The effect of corticosteroids on exercise-induced asthma. Journal of Allergy and Clinical Immunology, 54, 14.

McNeill, R. S., Nairn, J. R., Millar, J. S., and Ingram, C. G. (1966). Exercise-induced asthma. Quarterly Journal of Medicine, 35, 55.

Poppius, H. and Salorinne, Y. (1973). Comparative trial of Salbutamol and an anticholinergic drug, SCH 1000, in prevention of exercise-induced asthma. Scandinavian Journal of Respiratory Disease, 54, 142.

, and Viljanen, A. A. (1972). Inhalation of a new anticholinergic drug SCH 1000 , in asthma and chronic bronchitis: effect on airway resistance, thoracic gas volume, blood gases and exercise-induced asthma. Bulletin de Physio-Pathologie Respiratoire, 8, 643.

Silverman, M. (1973). Exercise studies on asthmatic children. M.D. thesis, University of Cambridge. and Anderson, S. D. (1972). Standardization of exercise tests in asthmatic children. Archives of Disease in Childhood, 47, 882. 
- and Andrea, T. (1972). Time course of effect of disodium cromoglycate on exercise-induced asthma. Archives of Disease in Childhood, 47, 419.

Sly, R. M., Heimlich, E. M., Busser, R. J., and Strick, L. (1967). Exercise-induced bronchospasm: effect of adrenergic or cholinergic blockade. Journal of Allergy, 40, 93.
Yu, D. Y. C., Galant, S. P., and Gold, W. M. (1972). Inhibition of antigen-induced bronchoconstriction by atropine in asthmatic patients. Journal of Applied Physiology, 32, 823.

Requests for reprints to: Dr. S. Godfrey, Department of Paediatrics and Neonatal Medicine, Hammersmith Hospital, Du Cane Road, London W12 0HS. 